\title{
Experimental simulation of dust mineralogy in CAMS
}

\author{
SAMUEL REMY
}

\section{HYGEOS}

Presenting Author: sr@hygeos.com

The Integrated Forecasting System (IFS) of ECMWF is core of the Copernicus Atmosphere Monitoring Service (CAMS) to provide global analyses and forecasts of atmospheric composition, including reactive gases, as well as aerosol and greenhouse gases. Desert dust is simulated globally in three size bins. This system has been extended in an experimental version to simulate prognostically twelve mineralogical components of dust, each of them in three size bins. These mineralogical components represent around $70 \%$ of the total dust mass (please see the distribution of dust emissions in the emissions of mineralogical components below). The chemical composition of dust can be derived from the mineralogical information, which provides burden, emissions and deposition fluxes of dust Iron, Calcium, Manganese etc. Each of the dust mineralogical component uses specific optical properties.

Four years of dust simulated global mineralogical and chemical composition have been produced. Iron from dust have been compared against observations of surface concentration worldwide and against simulations from the atmospheric iron model intercomparison organized by the Group of Experts on the Scientific Aspects of Marine Environmental Protection (GESAMP). Both evaluations gave satisfactory results. Surface concentration of other dust chemical components have been evaluated against surface observations other US and Europe.

Simulation of the dust mineralogy allows for a better representation of the geographical variation in dust absorption, especially depending on the simulated burden of the most absorbing species, hematite and goethite. The simulated variability in extinction is lower than that of absorption.

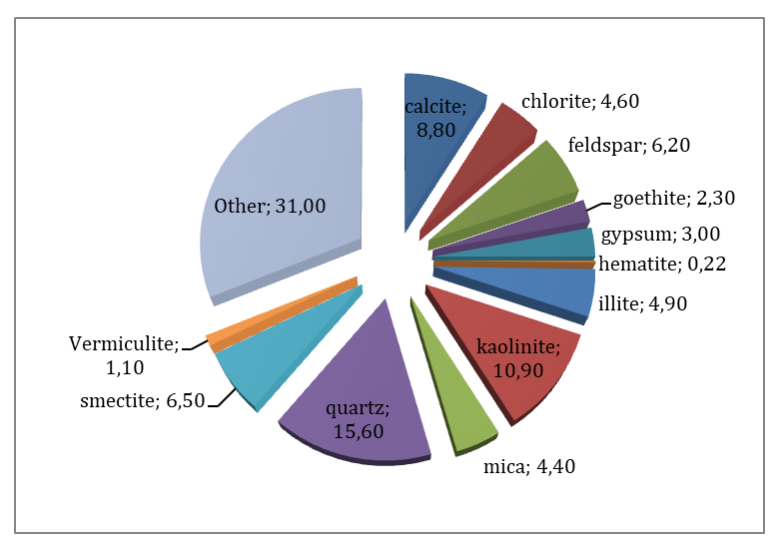

